\title{
A Study on the Positioning of Warehouse Logistics Industry in Yangtze River Region--Based on the Agglomeration Efficiency of Service Industry
}

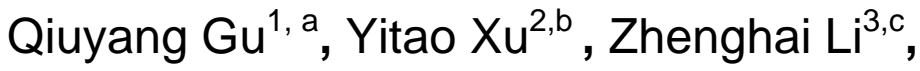 \\ Liyang $\mathrm{Zhu}^{4, \mathrm{~d}}$, Haowei $\mathrm{Xia}^{5, \mathrm{e}}$ \\ (Ningbo Dahongying University,Ningbo 315175) \\ ${ }^{1 \sim 5}$ No.899, Xueyuan Road, Yinzhou District, Ningbo City, Zhejiang Province, China \\ a827791171@qq.com, b627481594@qq.com, '961918800@qq.com \\ d452853904@qq.com, ${ }^{\mathrm{e}} 595863110 @ q q . c o m$
}

Keywords: warehouse logistics industry; agglomeration efficiency; Yangtze River

Abstract. The storage and logistics industry in the Yangtze River Delta region can draw lessons from the service industry, and exert the benefit of agglomeration to achieve the development of the logistics industry in the Yangtze River Delta region.

\section{Introduction}

As one of the most developed regions in China,Yangtze River Delta region has made great achievements in promoting regional economic development[1]. The contribution of finace to our country's social and economic covers heavy proportion. With the development of Warehousing and logistics technology, warehousing and logistics infrastructure and the concepts of warehousing and logistics, storage has become a constraint to the rapid development of the logistics industry. How to correctly understand the warehousing logistics, to promote the development of the logistics industry in the Yangtze River Delta region has become a inevitable problem that are waiting for us to think.

The logistics industry in the Yangtze River Delta. Due to the rapid economic development and openness in recent years in China, warehousing industry in Yangtze River Delta region enjoy good momentum of growth[2]. The construction of logistics warehouse infrastructure and service level have been greatly improved. The logistics industry of the Yangtze River Delta region has occupied a leading position in the country in terms of scale, equipment technology and business services.

Formation Mechanism and Problems Faced in the Development of storage industry Gathering Area in the Yangtze River region. In order to better seize the opportunity of the new round international logistics industry and to speed up the formation of regional warehousing and logistics cluster development trend[3], the main measures for the development of warehousing and logistics industry should be as follows:

First of all, The government should speed up the construction of storage and logistics industry infrastructure, accelerate the rational distribution of space layout and improve the overall economic efficiency of warehousing and logistics industry. Secondly, We need to coordinate research and accelerate the development of warehousing and logistics market. Thirdly,The government should optimize the design of a relatively good storage and logistics market environment,and improve the market rules. Lastly, the various measures of development of storage and logistics should be established in the Yangtze River Delta region. 

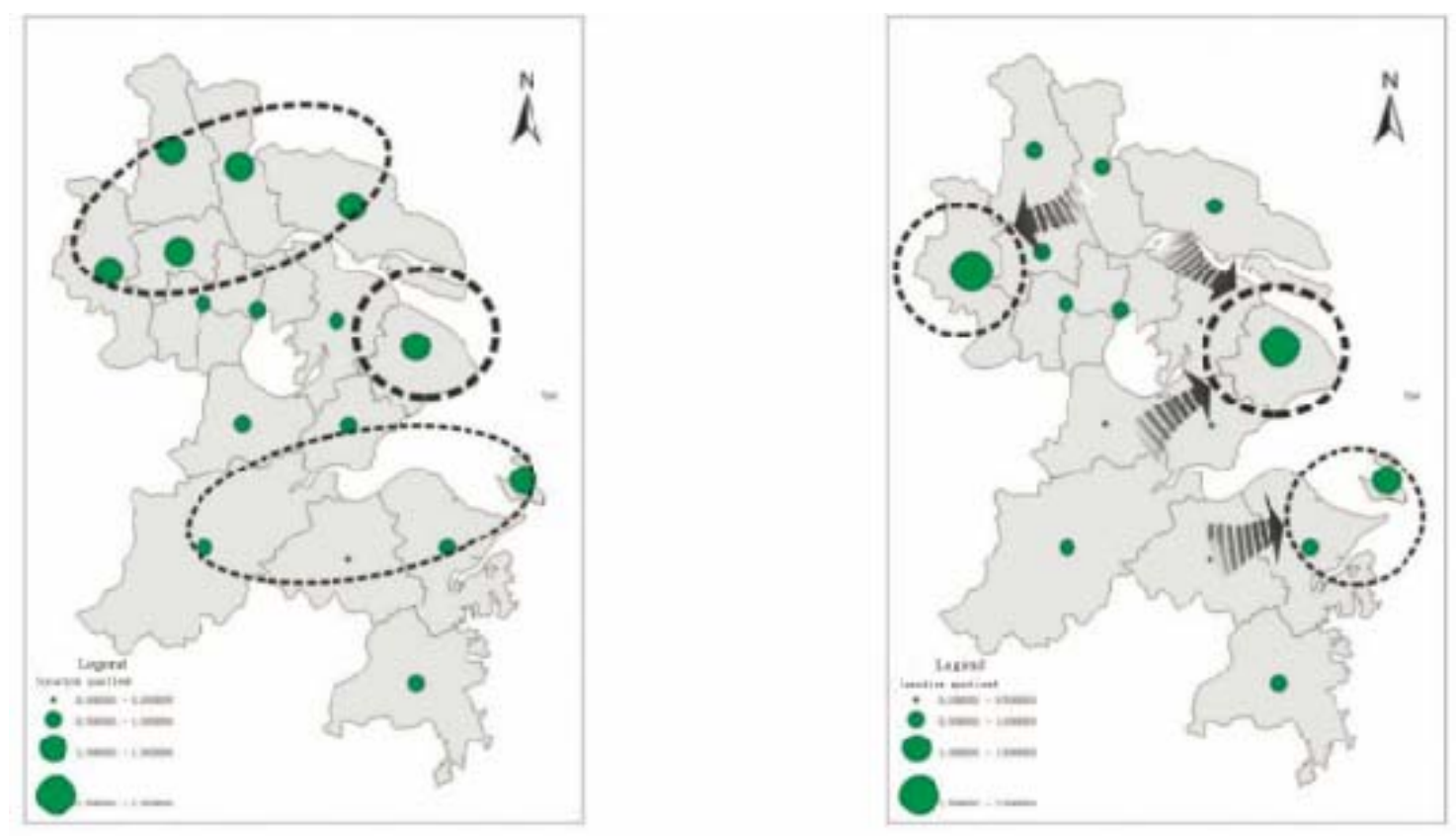

Fig. 1 Diagram of spatial agglomeration of logistics industry in Yangtze River Delta region from 2008 to 2015

A few policy suggestions on the positioning of warehouse logistics industry in the Yangtze River Delta region Based on the pattern of service of industry agglomeration. Yangtze River region is located in the center region of integrating logistics center networks in China, which requires us to accelerate the integration of logistics resources in this region to play a gathering efficiency. Therefore, the author believes that the government and companies should make efforts in the following areas to play the effectiveness of warehousing and logistics.

Strengthen the construction of storage and logistics infrastructure. It should accelerate the process of integration of storage and logistics facilities in the Yangtze River Delta region after drawing lessons from the cluster development models of the service industry[4]. To enable the rapid development of warehousing and logistics industry in Yangtze River Delta region, it need the transport industry to reach a high level to make the air transport, rail transport, road transport as the representative of the logistics network. So as to promote the logistics industry in the Yangtze River Delta region based on the basic transportation infrastructure, and further develop the efficiency of agglomeration.

Table 1 The number and proportion of enterprises in different sectors of logistics industry in Yangtze River Delta region in 2015

\begin{tabular}{cccccc}
\hline Type of enterprise & quantity & percentage & Type of enterprise & quantity & percentage \\
\hline $\begin{array}{c}\text { Railway } \\
\text { transportation } \\
\begin{array}{c}\text { Road } \\
\text { transportation }\end{array}\end{array}$ & 244 & 8.76 & $\begin{array}{c}\text { Pipeline } \\
\text { transportation }\end{array}$ & 67 & 2.41 \\
$\begin{array}{c}\text { urban public } \\
\text { transport } \\
\text { water }\end{array}$ & 873 & 31.35 & $\begin{array}{c}\text { Warehousing } \\
\text { logistics }\end{array}$ & 608 & 21.83 \\
$\begin{array}{c}\text { transportation } \\
\text { Air transportation }\end{array}$ & 143 & 5.14 & Post office & 107 & 3.84 \\
\hline
\end{tabular}



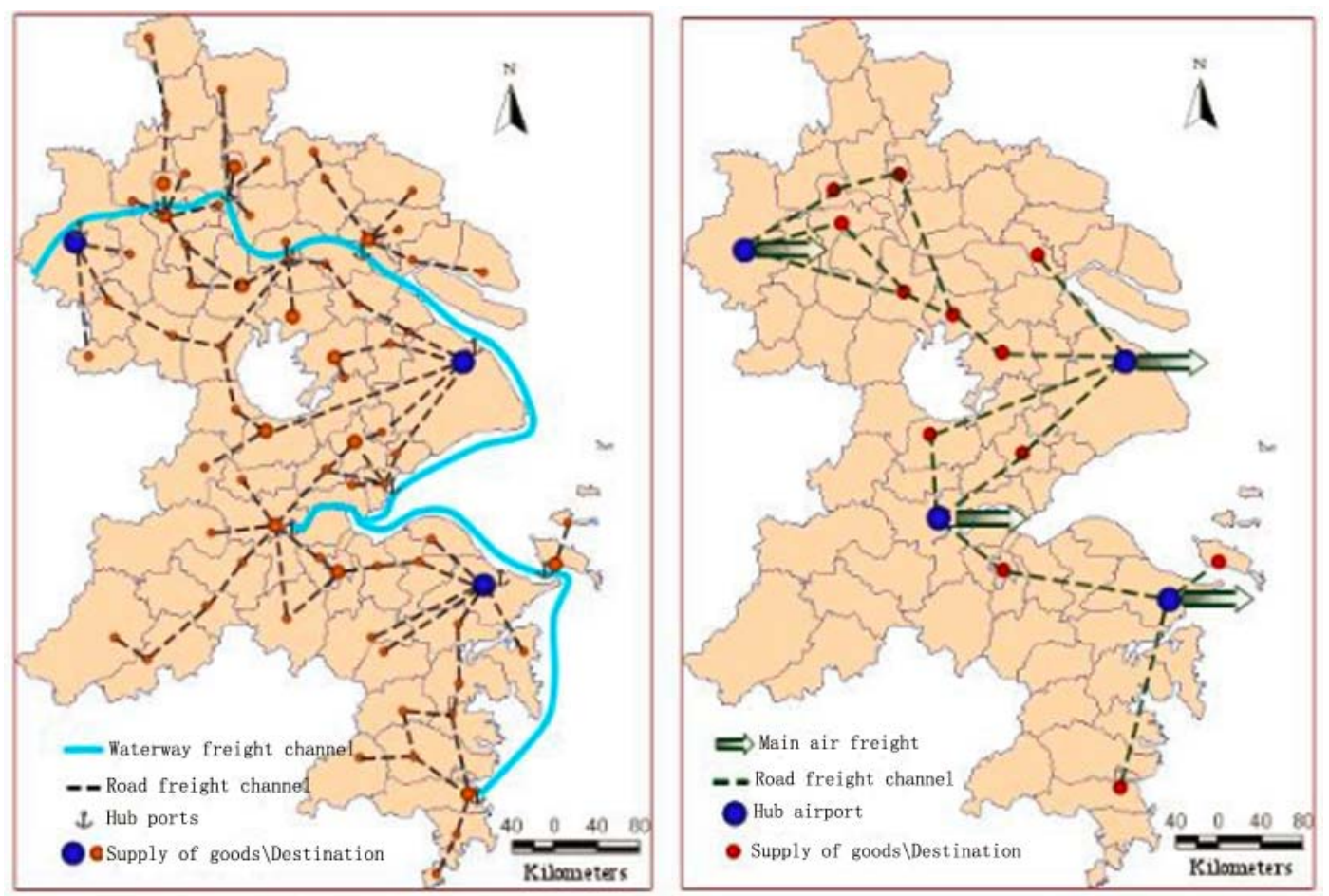

Fig. 2 The figure of JunctionsTransport in Yangtze River Delta region from 2008 to 2015

Accelerate the space layout of warehouse logistics park. Establish a logistics industry chain in the Yangtze River Delta region need to use of network information technology to carry out a comprehensive layout[5]. The main body through the logistics park service to achieve mutual coordination and strengthen cooperation.

Accelerate the integration of warehousing and logistics information. Give full play to the leading role of local government, to create a good economic, policy and cultural environment for the integration of the logistics industry in the Yangtze River Delta region. Governments at all levels need to speed up the establishment of inter-regional logistics information platform to realize the sharing of information resources between regional and inter-regional, and promote the international competitiveness of the logistics industry in the Yangtze River Delta region.

\section{Summary}

All in all, the accumulation and development of storage and logistics industry in the Yangtze River Delta region is the product of the development of the times, which is more in line with the requirements of the society for warehousing and logistics industry in the future[6]. The research on the development mode of warehousing logistics industry agglomeration is in the exploratory stage at present. We need to carry on a further research on various influence factors and development laws and establish a new model of gathering development of warehousing and logistics industry.

\section{Acknowledgements}

This work was financially supported by the National College Students' Innovative Entrepreneurial Training Plan--The Level of Warehouse Logistics Industry in Yangtze River Region time structure,mechanism and effect(21613001003)(adviser:, Lili Ma) and Ningbo Dahongying University.

\section{References}

[1] H Xie, SO Marxism. Pan-Yangtze River Delta's Economic Status Of the Unbalanced Development_—Based on the Contours of Regional Economic Development Research.Dj.M. Maric, P.F. Meier and S.K. Estreicher: Mater. Sci. Forum Vol. 83-87 (1992), p. 119. 
[2] X Chen,A Tale of Two Regions in ChinaRapid Economic Development and Slow Industrial Upgrading in the Pearl River and the Yangtze River Deltas: 《International Journal of Comparative Sociology》Vol.48-49(2007), p.167-201.

[3] V Thai, KB Ibrahim, R Vidya, HY Huang.Competency Profile of Managers in the Singapore Logistics Industry: 《Asian Journal of Shipping \& Logistics》Vol.28(2012), p.161-182.

[4] J Zheng, L Zhang, Y Wang. The underdevelopment of service industry in china: An empirical study of cities in Yangtze River Delta: 《Frontiers of Economics in China》 Vol.6(2011),p.413-446.

[5] X Pan, Y Kanaya, H Tanimoto, S Inomata, Z Wang.Examining the major contributors and controlling factors of ozone production in a rural area of the Yangtze River Delta region during harvest season: 《Atmospheric Chemistry \& Physics》Vol.14(2014), p.30913-30945.

[6] B Huang, M Wang, L Yan, W Sun, Y Zhao,Accumulation, transfer, and environmental risk of soil mercury in a rapidly industrializing region of the Yangtze River Delta, China: 《Journal of Soils \& Sediments》Vol.11(2011), p.607-618. 